\title{
Macular Thickness by Optical Coherence Tomography in Normal Togolese Melanoderma Subjects: A Case Study of 338 Eyes
}

\author{
Kossi Dzidzinyo ${ }^{*}$, Akoete Djagnikpo², Koffi Didier Ayena3 ${ }^{3}$ Kokou Vonor ${ }^{4}$, \\ Mawouli Ayodele Santos ${ }^{5}$, Kassoula Batomaguela Nonon-Saa1, Kokou Messan Amedome4, \\ Adam Nouhou-Diori' ${ }^{1}$, Nidain Maneh${ }^{6}$, Komi Balo $^{1}$
}

${ }^{1}$ Department of Ophthalmology, Sylvanus Olympio University Hospital, Lomé, Togo

${ }^{2}$ Sight \& Vision Ophthalmology Clinic, Lomé, Togo

${ }^{3}$ Department of Ophthalmology, Secondary Hospital of Bè, Lomé, Togo

${ }^{4}$ Department of Ophthalmology, Kara University Hospital, Kara, Togo

${ }^{5}$ Department of Ophthalmology, Regional Hospital Center of Aneho, Aneho, Togo

${ }^{6}$ Department of Ophthalmology, Campus University Hospital, University of Lomé, Lomé, Togo

Email: *dkbriceoph@gmail.com

How to cite this paper: Dzidzinyo, K., Djagnikpo, A., Ayena, K.D., Vonor, K., Santos, M.A., Nonon-Saa, K.B., Amedome, K.M., Nouhou-Diori, A., Maneh, N. and Balo, K. (2022) Macular Thickness by Optical Coherence Tomography in Normal Togolese Melanoderma Subjects: A Case Study of 338 Eyes. Open Journal of Ophthalmology, 12, 44-50.

https://doi.org/10.4236/ojoph.2022.121005

Received: December 29, 2021

Accepted: January 26, 2022

Published: January 29, 2022

Copyright $\odot 2022$ by author(s) and Scientific Research Publishing Inc. This work is licensed under the Creative Commons Attribution International License (CC BY 4.0).

http://creativecommons.org/licenses/by/4.0/ (c) (i) Open Access

\begin{abstract}
Objective: Maculopathies are more and more frequent. For the follow-up of its evolution and therapy, it seems important for us to determine the baseline in normal subjects by Optical Coherence Tomography (OCT). The goal here is to determine the acceptable range of macular thickness in normal black subjects in Lomé. Methodology: This is a retrospective study over a 6-month period. It did not include all patients with retinopathy of any cause, maculopathy, and glaucoma. The analyzed variables were the average macular thickness, the central macular thickness, and the total macular volume. Results: Out of the 433 macular OCT performed, 191 patients were selected; a total of 338 eyes. These included 96 men and 95 women. A sex ratio was 1.01. The median age was 44.1 years with extremes ranging from 10 to 70 years. The average macular thickness was $263.4 \mu \mathrm{m}$ for the right eye and $263.7 \mu \mathrm{m}$ for the left eye. The central macular thickness was $174.1 \mu \mathrm{m}$ for the right eye and $173.3 \mu \mathrm{m}$ for the left eye. The total macular volume was 7.4 in both eyes. Discussion: No significant statistical difference existed between the two sexes. The average macular thickness found in this study was within the range of normality observed in the literature, which is between 216 and $288 \mu \mathrm{m}$. Conclusion: The average macular thickness of the normal subject in Lomé was $263.4 \mu \mathrm{m}$.
\end{abstract}

\section{Keywords}

Macular Thickness, OCT, Normal Subject 


\section{Introduction}

The macula is the region of the retina that is most remarkable due to the role it plays in vision. It provides the eye with a better visual acuity if it is healthy, and also accommodates discriminative vision, precision vision, as well as color vision. These functions are made possible by its anatomical presentation and the presence of photoreceptor cells: the cones.

The macular examination has evolved over time. It is accessible by direct and indirect ophthalmoscopy. The latter is used to see the relief and to detect subfoveolar deposits or oedemas. It is also possible to explore by retinography and retinal angiofluorography. Today, there is a more sophisticated tool than the previous ones and especially non-invasive which allows measuring the macular thickness and whose resolution is close to histology.

Any anatomical and pathological change in the macula will be reflected in the variation of its thickness. As a result, the measurement of macular thickness is becoming a diagnostic and monitoring criterion for maculopathy in diabetic retinopathy, Irvine Gass syndrome, age-related macular degeneration, and the impact of retinal vascular occlusions.

Therefore, it is necessary to have a normative database for comparison and analysis in pathological situations.

In the western literature, there are figures for macular thickness in leucoderma [1], in Asian people [2].

Can we transpose the standard from one race to another? No. Macular thickness is known to vary according to race and other factors such as age and sex [3]. Recently, an African study [4] addressed this issue. The author did not find any variation in macular thickness according to sociodemographic and clinical characteristics. As a limitation, he mentioned the size of his sample and suggested another observation with a significant size.

This study aims to evaluate the acceptable range of macular thickness in normal Togolese subjects and study its variability according to sex and age.

\section{Methodology}

Our study was conducted in a private ophthalmologic center located in Lome, the capital city of Togo, West Africa. It is a retrospective and analytical study. This study ran from September 2019 through February 2020, within a period of six months. It was carried out in accordance with the Declaration of Helsinki.

The study involved the analysis of patients' records received as part of a routine check-up. The patients should have a visual acuity of $10 / 10^{\text {th }}$ Parinaud 2 without correction for those under 40 years of age and Parinaud 2 with near correction for presbyopes. Intraocular pressure should be less than $21 \mathrm{~mm} \mathrm{Hg}$. Patients with retinopathy or maculopathy on the fundus, whatever the etiology, were not included in this study, nor were patients with glaucomatous optic neuropathy or any other etiology. The selected patients should not have undergone any ocular surgery. 
Our patients had an OCT examination after a drop of tropicamide in the absence of contraindication. Dilatation helped for easier and better-quality acquisition. Only acquisitions with signal strength greater than 30 were considered. The patients were given as much information as possible about the purpose, the principle, and the modalities of the examination. The patients were reassured through a clear and accurate explanation of the process. They were also informed about the importance of maintaining the fixation, inside the lens, of the light test pattern whose perception will become clearer as the automatic focusing process progresses, as well as about the necessity to avoid tracking the different scans with eyes. The forehead and the chin were immobile during the entire process. The device used was the 3D OCT-Maestro from Topcon (Japan). For each eye understudy, we performed acquisitions in automatic volume mode "macular cube" with horizontal B-scans covering a macular region of $6 \times 6 \mathrm{~mm}$. The measurements were automatic (mapping). In addition to the mapping, we also performed EDI acquisitions: Enhanced Depth Imaging-OCT to improve the image sharpness and to detect any abnormalities in the different macular structures.

The variables studied were: age, sex, average macular thickness, central macular thickness, and total macular volume.

The data were compiled with Microsoft EXCEL software. Data analysis was done with SPSS 2.4 software. The data were presented in average, standard deviation, and $95 \%$ confidence interval for comparison of variables. The statistical tests used were the chi-square.

\section{Results}

\subsection{Sociodemographic Characteristics}

Out of 433 macular OCT performed, 191 patients had been retained, a total of 338 eyes. The lateral aspect indicates 171 right eyes for 167 left eyes. There were 96 males and 95 females, for a sex ratio of 1.01. The median age was 44.1 years +/- 14.95 with extremes ranging from 10 to 70 years. The most represented age groups were 40 - 49 and 50 - 59 years. These latter accounted for $48.2 \%$ of the total number of patients.

\subsection{Macular Measurement Data}

The average macular thickness was $263.4 \mu \mathrm{m}$ for the right eye and $263.7 \mu \mathrm{m}$ for the left eye. The variation in the average macular thickness according to sex was $263.45 \mu \mathrm{m}$ for men and $262.69 \mu \mathrm{m}$ for women. It was not statistically significant $(p=0.603)$. Similarly, the variation in central macular thickness and macular volume with respect to sex was not significant. The respective P-values were 0.109 and 0.627 . Table 1 shows the distribution of average, central thickness, and macular volume according to sex. Central macular thickness was $174.1 \mu \mathrm{m}$ for the right eye and 173.3 for the left eye. The total macular volume was 7.4 for the right eye and 7.45 for the left eye. In contrast, the study of the variation of the average 
Table 1. Distribution of average, central thickness, and macular volume according to sex and their significance.

\begin{tabular}{ccccc}
\hline $\begin{array}{c}\text { Macular } \\
\text { measurement data }\end{array}$ & Sex & Average & Standard deviation & p-value \\
\hline Average macular & Male & 263.45 & 10.84 & \\
thickness $(\mu \mathrm{m})$ & Female & 263.34 & 9.25 & 0.603 \\
& Total & 263.40 & 10.06 & \\
\hline $\begin{array}{c}\text { Central macular } \\
\text { thickness }(\mu \mathrm{m})\end{array}$ & Male & 174.58 & 12.02 & 0.109 \\
\hline & Tomale & 171.8 & 12.41 & \\
Macular volume & Male & $\mathbf{1 7 3 . 8 4}$ & 12.7 & \\
$\left(\mathrm{~mm}^{3}\right)$ & Female & 7.44 & 0.31 & 0.627 \\
& Total & 7.43 & 0.27 & \\
\hline
\end{tabular}

macular thickness $(\mathrm{p}<0.001)$ and macular volume $(\mathrm{p}<0.001)$ with age was highly significant. The average macular thickness and macular volume decrease with age. Table 2 shows the distribution of average and central thicknesses and macular volume according to age. Only the variation of central macular thickness with age was not significant $(\mathrm{p}=0.441)$.

\section{Discussion}

The macula is a remarkable area of the retina, the examination or analysis of which can inform us and especially explain certain drops in vision. One of the objective criteria in its analysis is to determine its thickness.

\subsection{Sociodemographic Characteristics}

In the below cases, men and women were represented in the same proportions.

The median age was 44.1 years $+/-14.95$. This average was high as compared to Abdu in Nigeria [5] and Ka in Senegal [4] who found 36.4 and 27.39 years respectively. The latter was a study that involved a population whose age varied between 18 and 40 years, whereas our sample was more extended (10 and 70 years). On the other hand, this average is close to the observation made by Duan [2], of the order of 46.4 years, which was an epidemiological study and concerned a population of 30 to 85 years.

\subsection{The Average Macular Thickness}

The average macular thickness was $263.3 \mu \mathrm{m}$ for the right eye and $263.7 \mu \mathrm{m}$ for the left. It is similar to that found by Ka in Senegal [4], and Wesler in Norway [1]. The difference between the 2 sexes was not statistically significant ( $\mathrm{p}=$ 0.603). The Norwegian [1] and Saudi [3] studies found a significant difference between the two sexes. The study of the variation of the average thickness was a function of age $(p<0.001)$. It was noted that the average macular thickness 
Table 2. Distribution of average and central thicknesses and macular volume according to age groups and their significance.

\begin{tabular}{|c|c|c|c|c|}
\hline $\begin{array}{c}\text { Macular } \\
\text { measurement data }\end{array}$ & Age group (years) & Average & Standard deviation & $\mathrm{p}$-value \\
\hline \multirow{7}{*}{$\begin{array}{l}\text { Average macular } \\
\text { thickness }(\mu \mathrm{m})\end{array}$} & $10-19$ & 270.75 & 8.19 & \multirow{7}{*}{$<0.01$} \\
\hline & $20-29$ & 268.27 & 8.81 & \\
\hline & $30-39$ & 266.87 & 8.35 & \\
\hline & $40-49$ & 265.86 & 7.77 & \\
\hline & $50-59$ & 259.98 & 8.84 & \\
\hline & $\geq 60$ & 252.98 & 8.87 & \\
\hline & Average & 263.40 & 10.06 & \\
\hline \multirow{7}{*}{$\begin{array}{l}\text { Central macular } \\
\text { thickness }(\mu \mathrm{m})\end{array}$} & $10-19$ & 173.88 & 8.51 & \multirow{7}{*}{0.44} \\
\hline & $20-29$ & 176.53 & 14.07 & \\
\hline & $30-39$ & 171.80 & 9.15 & \\
\hline & $40-49$ & 171.89 & 13.71 & \\
\hline & $50-59$ & 176.46 & 15.43 & \\
\hline & $\geq 60$ & 173.16 & 10.48 & \\
\hline & Average & 173.84 & 12.7 & \\
\hline \multirow{7}{*}{$\begin{array}{l}\text { Macular volume } \\
\qquad\left(\mathrm{mm}^{3}\right)\end{array}$} & $10-19$ & 7.62 & 0.26 & \multirow{7}{*}{$<0.01$} \\
\hline & $20-29$ & 7.58 & 0.25 & \\
\hline & $30-39$ & 7.56 & 0.27 & \\
\hline & $40-49$ & 7.52 & 0.22 & \\
\hline & $50-59$ & 7.34 & 0.26 & \\
\hline & $\geq 60$ & 7.15 & 0.26 & \\
\hline & Average & 7.43 & 0.29 & \\
\hline
\end{tabular}

became thinner with age. This is in line with the findings of Pokharel [6] and Al-zamil [3].

\subsection{The Central Macular Thickness}

The central macular thickness in our case was $174 \mu \mathrm{m}$. It is close to that of Wesler [1] which was $178 \mu \mathrm{m}$. On the other hand, it was higher than that of Abdu [5] which was $149.58 \mu \mathrm{m}$. The study of the variation of the central thickness of the macula was not a function of age $(\mathrm{p}=0.44)$. There was no statistically significant difference between the 2 sexes $(\mathrm{p}=0.627)$.

\subsection{The Macular Volume}

The macular volume found was $7.4 \mathrm{~mm}^{3}$. It was higher than that of $\mathrm{Abdu}$ [5] and Duan [2] which were respectively 6.79 and $6.76 \mathrm{~mm}^{3}$. It should be noted that the results depend on the machine used, according to Giani [7]. The two studies mentioned above used the Cirrus OCT stratus from Zeiss. The macular volume 
was clearly lower than that of Pokharel [6] and Al-zamil [3] who found 8.53 and $8.48 \mathrm{~mm}^{3}$ respectively. The former used a Heidelberg spectralis and the latter a Cirrus Zeiss SD OCT which had a higher resolution. There was no significant difference between the sexes $(\mathrm{p}=0.109)$, but the volume decreased with age $(\mathrm{p}<$ $0.001)$.

\subsection{Limits of the Study}

The limitation of our study includes: the non-random selection of eyes; the enrollment of the only eye (right or left) of 44 subjects who had only single normal eye could have induced bias [8]. So our study did not take into account axial lengths or refractions that could affect the analysis of the data. We assure that our study population did not have high ametropia since the visual acuities without correction were good. However, our sample has the advantage of having covered all ages and allows us to get an idea of the macular thickness of the normal subject.

\section{Conclusion}

The normal subject's macular thickness in Togo is on the order of $263.4 \mu \mathrm{m}$ as previously observed. The three parameters studies: average macular thickness, central macular thickness and macular volume; do not vary by sex. Apart from the central macular thickness, they decrease with age. Given the high prevalence of glaucoma in relatively young subjects in our practice context in sub-Saharan Africa, studies on macular thickness in glaucomatous subjects versus normal subjects would be very helpful and complement these data.

\section{Ethical Approval}

Approval for the study was obtained from the National Medical Ethic Committee.

\section{Conflicts of Interest}

The authors declare no conflict of interest.

\section{References}

[1] Wexler, A., Sand, T. and Elsas, T.B. (2010) Macular Thickness Measurements in Healthy Norwegian Volunteers: An Optical Coherence Tomography Study. BMC Ophthalmology, 10, 13. https://doi.org/10.1186/1471-2415-10-13

[2] Duan, X.R., Liang, Y.B., Friedman, D.S., et al. (2010) Normal Macular Thickness Measurements Using Optical Coherence Tomography in Healthy Eyes of Adult Chinese Persons: The Handan Eye Study. Ophthalmology, 117, 1585-1594. https://doi.org/10.1016/j.ophtha.2009.12.036

[3] Al-Zamil, W.M., Al-Zwaidi, F.M. and Yassin, S.A. (2017) Macular Thickness in Healthy Saudi Adults: A Spectral-Domain Optical Coherence Tomography Study. Saudi Medical Journal, 38, 63-69. https://doi.org/10.15537/smj.2017.1.17565

[4] Ka, A.M., Diagne, J.P., Wane, A.M. et al. (2019) Evaluation de l'épaisseur maculaire moyenne par la tomographie en cohérence optique (SD OCT) chez le sujet mélano- 
derme sénégalais. Journal Français d Ophtalmologie, 42, 170-176.

https://doi.org/10.1016/j.jfo.2018.09.005

[5] Abdu, L. and Sani, R.Y. (2014) Macular Volume and Central Foveal Thickness Measurements in Normal Eyes of Healthy Nigerian Adults Using Optical Coherence Tomography. Annals of African Medicine, 13, 134-137.

https://doi.org/10.4103/1596-3519.134417

[6] Pokharel, A., Shrestha, G.S. and Shrestha, J.B. (2016) Macular Thickness and Macular Volume Measurements Using Spectral Domain Optical Coherence Tomography in Normal Nepalese Eyes. Clinical Ophthalmology, 10, 511-519.

https://doi.org/10.2147/OPTH.S95956

[7] Giani, A., Cigada, M., Choudhry, N. et al. (2010) Reproducibility of Retinal Thickness Measurements on Normal and Pathologic Eyes by Different Optical Coherence Tomography Instruments. American Journal of Ophthalmology, 150, 815-824. https://doi.org/10.1016/j.ajo.2010.06.025

[8] Murdoch, I.E., Morris, S.S. and Cousens, S.N. (1998) People and Eyes: Statistical Approach in Ophthalmology. British Journal of Ophthalmology, 82, 971-973. https://doi.org/10.1136/bjo.82.8.971 